\title{
Major Salivary Gland Cancer pN2 TNM Finding V8
}

National Cancer Institute

\section{Source}

National Cancer Institute. Major Salivary Gland Cancer pN2 TNM Finding V8. NCI

Thesaurus. Code C132757.

Major salivary gland cancer with metastasis in a single ipsilateral lymph node, $3 \mathrm{~cm}$ or less in greatest dimension and $\mathrm{ENE}(+)$; or more than $3 \mathrm{~cm}$ but not more than $6 \mathrm{~cm}$ in greatest dimension and ENE(-); or metastases in multiple ipsilateral lymph nodes, none more than $6 \mathrm{~cm}$ in greatest dimension and ENE(-), or in bilateral or contralateral lymph nodes, none more than $6 \mathrm{~cm}$ in greatest dimension and ENE(-). (from AJCC 8th Ed.) 